Article

\title{
Discovery of a Novel Cationic Surfactant: Tributyltetradecyl-Phosphonium Chloride for Iron Ore Flotation: From Prediction to Experimental Verification
}

\author{
Pan Chen ${ }^{1}$, Yuehua Hu ${ }^{1}$, Zhiyong Gao ${ }^{1}{ }^{(1)}$, Jihua Zhai ${ }^{1}$, Dong Fang ${ }^{2}$, Tong Yue ${ }^{1}$, \\ Chenyang Zhang ${ }^{1,3, *}$ (iD) and Wei Sun ${ }^{1, *}$ \\ 1 School of Minerals Processing and Bioengineering, Central South University, Changsha 410083, China; \\ panchen@csu.edu.cn (P.C.); huyuehuacsu@126.com (Y.H.); zhiyong.gao@csu.edu.cn (Z.G.); \\ jihuazhai@csu.edu.cn (J.Z.); yuetong@cus.edu.cn (T.Y.) \\ 2 Xtalpi Inc., Shenzhen 518040, China; dong.fang@xtalpi.com \\ 3 Institute of Theoretical and Computational Chemistry, School of Chemistry and Chemical Engineering, \\ Nanjing University, Nanjing 210023, China \\ * Correspondence: zhangchenyang@csu.edu.cn (C.Z.); sunmenghu@csu.edu.cn (W.S.); \\ Tel.: +86-155-7315-6566 (C.Z.); +86-0731-8883-6873 (W.S.)
}

Received: 28 October 2017; Accepted: 28 November 2017; Published: 2 December 2017

\begin{abstract}
In this work, tributyltetradecyl-phosphonium chloride (TTPC), has been first introduced to be a novel and efficient cationic surfactant for cationic reverse flotation separation of quartz from magnetite. The first-principles density functional theory calculations, Zeta potential measurements and adsorption isotherm measurements consistently predict that TTPC may be a promising collector that is better than dodecyl triethyl ammonium chloride (DTAC), based on the facts that TTPC and DTAC both prefer to physically adsorb on the quartz surface owing to electrostatic force, but the active part $\left(\mathrm{P}^{+}\left(\mathrm{C}_{4} \mathrm{H}_{9}\right)_{3}\right)$ of TTPC takes much more positive charges than that $\left(\mathrm{N}^{+}\left(\mathrm{CH}_{3}\right)_{3}\right)$ of DTAC. The micro-flotation and Bench-scale flotation results further verify that TTPC presents a stronger collecting power and much better selectivity for iron ore reverse flotation in comparison to the conventional collector DTAC. Furthermore, the corresponding adsorption mechanism of TTPC on the quartz have also been investigated in detail. This work might show a good example to discover a potential candidate collector by analogy with a known excellent collector based on reasonable prediction.
\end{abstract}

Keywords: quaternary phosphonium salts; quaternary ammonium salts; flotation collectors; prediction; density functional theory

\section{Introduction}

Flotation is the most effective and economical technology to further upgrade iron concentrates [1]. Intensive investigations on iron ore flotation began in America in the 1930s. There are five major types of flotation routes for iron ore, which have been developed to remove silica from iron minerals, including cationic flotation of iron oxide, cationic reverse flotation of quartz, anionic flotation of iron oxide, anionic reverse flotation of quartz, and their combination [2]. Since anionic collectors such as petroleum sulphonate, fatty acids, and hydroxamates have been first used in the direct flotation of iron oxides in the 1950s [1], the applications of anionic collectors in iron ore flotation have been achieved significant progress. However, due to advantages of reverse cationic flotation over anionic flotation, including the higher process selectivity and rates, as well as satisfactory results when hard water is used, the reverse cationic flotation route has become the most typical flotation route in the 
iron ore industry [3-7]. However, there are only very few types of cationic collectors (quaternary ammonium salt and their derivatives, with $\mathrm{N}$ atoms as the activation center) that can be used to float out silicate gangues in iron ore flotation [8-10]. This severely limits the development of cationic flotation technology used in iron ore beneficiation. Recently, the general method to improve flotation efficiency is to add huge amounts of depressants with various amines collectors in iron ore flotation [11-15]. However, adding high concentration depressants may affect the subsequent procedures and even contaminate the environment. Therefore, it is still highly desirable to predict and identify more novel and efficient cationic collectors for iron ore flotation.

As widely used in the fields of material and medicine, computational methods, such as quantum chemistry calculation and molecular dynamics simulation, have become very valuable tools for discovering and screening new materials and drugs [16-19]. Computational methods have also been extensively used in the field of flotation chemistry to understand the nature of physical chemistry in flotation process [20] and to guide the design and synthesis of flotation reagents [21,22]. However, it remains much more challenging to just computationally discover and screen more efficient flotation reagents in mineral processing because the flotation systems are usually too complicated for conventional computational methods. Alternatively, in this study, by drawing analogy with known excellent collector (DTAC), we aim to discover a novel collector based on reasonable prediction and experimental verification.

Both quaternary ammonium salts and quaternary phosphonium salts, which possess analogous molecular structures (they can be formulated as $\left(\left(\mathrm{NR}_{4}\right)^{+} \mathrm{L}^{-}\right)$and $\left(\left(\mathrm{PR}_{4}\right)^{+} \mathrm{L}^{-}\right)$, respectively, $\mathrm{R}$ groups may be the same or different alkyl or aryl group, $\mathrm{L}^{-}$is halide ion), have been widely used within the fields of antimicrobial, catalysis, and surface modification due to their good chemical stability and excellent electrical properties [23-25]. In the field of mineral processing, there are also intense investigations on flotation of quartz from iron ore using quaternary ammonium salts collectors [26]. However, there are almost no reports about the applications of quaternary phosphonium salts as collectors in iron ore beneficiation, and some attempts have been made in our previous work [27]. The motivation of the present work is to explore the practicability that adopting tributyltetradecyl-phosphonium chloride as an effective collector in iron ore flotation, by drawing analogy with an excellent cationic collector: dodecyl triethyl ammonium chloride (DTAC, the effective cation is denoted as DTA ${ }^{+}$).

It is reported that quantum-chemical parameters such as atomic charges, highest occupied molecular orbital (HOMO) and lowest unoccupied molecular orbital (LOMO) have a significant value in explaining reactivity of a reagent. $\mathrm{HOMO}$ is usually used to assess its chemical reactivity for a given molecule. LUMO is often relevant to the capacity of a collector accepting d-orbital electrons from a mineral. The atomic charges of active atoms in a collector contribute significantly to its electrostatic interaction to mineral surfaces $[28,29]$. Thus, in this study, the first-principles density functional theory (DFT) calculations at wB97XD [30] /Def2-TZVP [31] level are performed for both $\mathrm{TTP}^{+}$and $\mathrm{DTA}^{+}$to obtain their HOMO, LUMO, and atomic charges. Then, the interaction force of TTPC with quartz and its collecting capacity will be evaluated by analogy with DTAC in their HOMO, LUMO, and NPA charges.

To support the computational results, Zeta potential measurements and adsorption isotherm measurements will be also carried out. Based on the results from DFT calculations, Zeta potential measurements, and adsorption tests, the flotation performance of TTPC as collector will be predicted for iron ore reverse flotation in comparison with DTAC. Then, in the sections of Micro-flotation tests and Bench-scale flotation tests, the selectivity and collecting capability of TTPC will be further evaluated by analogy with DTAC. Furthermore, interfacial adsorption mechanisms of TTPC and DTAC on quartz surface will be investigated based on the isotherm measurements, according to the four-region model proposed by Somasundaran and Fuerstenau [32,33]. 


\section{Methodology}

\subsection{Materials and Reagents}

The quartz and magnetite sample was obtained from Hebei province in China. The sample was crushed, hand-selected, and ground in a porcelain mill. The ground samples were wet-sieved, and the fractions with the dimension of $-0.074 \mathrm{~mm}$ were collected and used in flotation tests. A portion of the fraction particles were further ground in an agate mortar to obtain particles with the dimension of $0.0005 \mathrm{~mm}$ for zeta potentials measurements. Chemical composition of quartz and magnetite involved in the current work is given in Table 1.

Table 1. Chemical composition of the pure minerals (wt \%).

\begin{tabular}{cccccc}
\hline Sample & Total Fe & $\mathrm{SiO}_{\mathbf{2}}$ & $\mathbf{A l}_{\mathbf{2}} \mathbf{O}_{\mathbf{3}}$ & $\mathrm{CaO}$ & $\mathrm{MgO}$ \\
\hline Quartz & 0.57 & 96.97 & 1.88 & 0.05 & 0.03 \\
Magnetite & 68.64 & 2.66 & 1.31 & 0.43 & 0.20 \\
\hline
\end{tabular}

The collector, tributyltetradecyl-phosphonium chloride (TTPC, molecular mass 435.15) in analytical grade, was provided from the Response-Chem Specialty Chemical Technologies Co., Ltd. (Beijing, China). Dodecyl triethyl ammonium chloride (DTAC, molecular mass 263.89) provided from the XiaMen Pioneer Technology Co., Ltd. (Xiamen, China) has been examined as comparison. The chemical structures of conventional surfactant DTAC and quaternary phosphonium surfactant TTPC are shown in Figure 1a,b, respectively. $\mathrm{HCl}$ and $\mathrm{NaOH}$ solutions in analytical grade are used as $\mathrm{pH}$ modifiers. The distilled water is utilized in all the experiments.

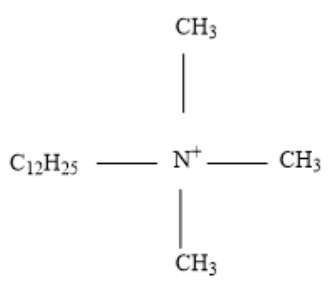

(a)

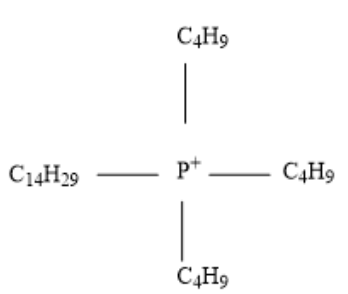

(b)

Figure 1. Schematic diagram of chemical structures of the dodecyl triethyl ammonium chloride $\left(\mathrm{DTA}^{+}\right)$

(a) and tributyltetradecyl-phosphonium chloride $\left(\mathrm{TTP}^{+}\right)(\mathbf{b})$.

\subsection{The DFT Calculations}

Hybrid DFT calculations were performed using D01 version of Gaussian 09 (Gaussian, Inc., Wallingford, CT, USA) [34] to elucidate the geometric and electronic structures of $\mathrm{DTA}^{+}$and $\mathrm{TTP}^{+}$. All the calculations employed a tight self-consistent field (SCF) energy convergence of $10^{-8}$ and an ultrafine grid for numerical integration. Firstly, the initial molecular models of $\mathrm{DTA}^{+}$and $\mathrm{TTP}^{+}$were constructed by Gaussian View 5.0 (Gaussian, Inc., Wallingford, CT, USA) [34]. Then, the molecular structures of $\mathrm{DTA}^{+}$and $\mathrm{TTP}^{+}$were primarily optimized by using D01 version of Gaussian 9.0 [34] at B3LYP [35] /6-31G(d) [36] level. The obtained molecular structures were further optimized at wB97XD [30] /Def2-TZVP [31] level. The Mulliken [37] and NPA (nature population analysis) [38] charges of DTA ${ }^{+}$ and $\mathrm{TTP}^{+}$as well as the frontier molecular orbitals (HOMO and LUMO) [39] and isostatic electronical potential have been obtained based on the finally optimized molecular structures. 


\subsection{Zeta Potential Measurements}

Zeta potential was measured at $20{ }^{\circ} \mathrm{C}$ using a Coulter Delsa-440SX zeta potential analyzer (Brookhaven Corporation, Long Island, NY, USA). A freshly-ground $0.05 \mathrm{~g}$ mineral sample $(-0.0005 \mathrm{~mm})$ was dispersed in $500 \mathrm{~mL}$ of $0.01 \mathrm{M} \mathrm{KCl}$ electrolyte solution and mixed for $5 \mathrm{~min}$, followed by the additions of $\mathrm{pH}$ regulators and the collector. The suspension was then allowed to settle for $5 \mathrm{~min}$, ensuring that the coarse mineral particles were sufficiently settled [40]. The supernatant containing the fine particles were transferred into a folded capillary cell, which ensured that there were no bubbles in the cell. The results presented here were the average of three independent measurements.

\subsection{Adsorption Tests}

The adsorption experiments in the present study were all performed under a TOC (total organic carbon) analyzer (Shimadzu Corporation, Kyoto, Japan). A $2.0 \mathrm{~g}$ of quartz mineral sample $(-0.074 \mathrm{~mm})$ was placed in a $250 \mathrm{~mL}$ conical flask and dispersed in $40 \mathrm{~mL}$ of quaternary phosphonium/ammonium salt solution with various of concentration at $\mathrm{pH}$ about 6.5 using a magnetic stirring apparatus DF-101S (LICHEN Corporation, Shanghai, China). Then, the suspension was mixed in an incubator shaker SHA-82A (Putian Corporation, Changzhou, China) at $140 \mathrm{r} / \mathrm{min}$ and $25^{\circ} \mathrm{C}$ for $40 \mathrm{~min}$. The solid particles were separated by centrifugation for $15 \mathrm{~min}$ at $9000 \mathrm{r} / \mathrm{min}$. The concentration of reagents in the supernatant was measured using a TOC-V CPH analyzer (Shimadzu Corporation, Kyoto, Japan). The adsorption of reagents on the mineral surface was calculated using the following equation:

$$
\Gamma=\left(\left(\mathrm{C}_{0}-\mathrm{C}\right) \times \mathrm{V}\right) / \mathrm{M}
$$

where $\Gamma$ is the adsorption quantity, $\mathrm{mol} / \mathrm{g} ; \mathrm{C}_{0}$ and $\mathrm{C}$ are the initial concentration and the supernatant concentration, respectively; $\mathrm{V}$ is the solution volume; and $\mathrm{M}$ is the mass. In all cases, at least three successive measurements were performed. The results presented here were the average of three independent measurements.

\subsection{Micro-Flotation Tests}

Micro-flotation tests of pure minerals and artificially mixed minerals were both conducted. The mixture contained magnetite and quartz with a mass ratio of 4:1. The flotation tests were all conducted in a $40 \mathrm{~mL}$ plexiglass cell using an XFG-type flotation machine purchased from Prospecting Machinery Factory, Jilin, China. For each experiment, $2 \mathrm{~g}$ of mineral sample was used at a spindle speed of $1700 \mathrm{rpm}$. The $\mathrm{pH}$ of the mineral suspension was adjusted to the desired operating value by adding $\mathrm{HCl}$ or $\mathrm{NaOH}$ stock solutions, followed by the addition of the collector with known concentration. Each stage had a 3 min conditioning period prior to the next reagent addition. Flotation concentrates were then collected for a total of $4 \mathrm{~min}$. The floated and unfloated particles were collected, filtered, and dried. In pure mineral flotation, the recovery was calculated based on solid weight distributions between the two products. For the artificially mixed minerals, the concentrates and tailings were filtered, dried, weighted, sampled, and assayed for $\mathrm{Fe}$ and $\mathrm{SiO}_{2}$.

\subsection{Bench-Scale Flotation}

Bench-scale flotation tests were performed in an XFD type flotation cell (self-aeration) of which the volume for rougher flotation and cleaner flotation were $1.5 \mathrm{~L}$ and $1 \mathrm{~L}$, respectively [41]. $500 \mathrm{~g}$ actual magnetite ores $(-0.074 \mathrm{~mm}, 90 \%)$ were used in the rougher flotation with a speed of $1650 \mathrm{r} / \mathrm{min}$. The flotation conditions and the closed flotation flowsheet of were detailed in Figure 2. The final concentrates and tailings were filtered, dried, weighted, sampled, and assayed for Fe and $\mathrm{SiO}_{2}$, respectively. 


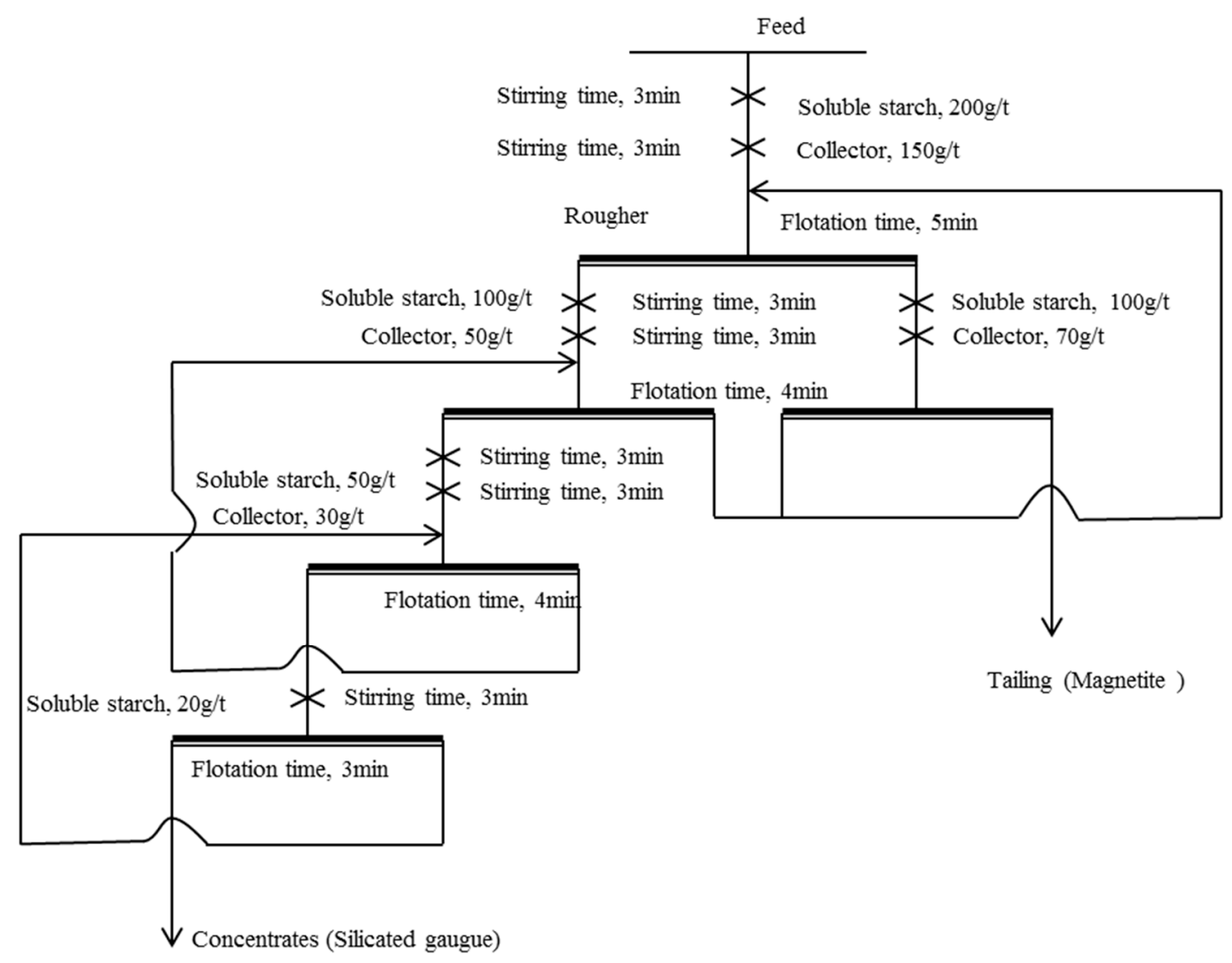

Figure 2. The locked cycle flowsheet of Bench-scale flotation experiments.

\section{Results and Discussions}

\subsection{The DFT Calculations}

To compare $\mathrm{TTP}^{+}$with $\mathrm{DTA}^{+}$at atomic and molecular level, the density functional theory calculations were performed to obtain some useful parameters (such as charges, electrostatic potential, $\mathrm{HOMO}$, and LUMO), which may be related to the collecting efficiency of a given collector. The optimized geometries of DTA ${ }^{+}$and $\mathrm{TTP}^{+}$cationic collectors at wB97XD/Def2-TZVP level are shown in Figure 3. It should be mentioned that $w B 97 X D$, which includes empirical dispersion and long-range corrections [30], could give a better description than traditional functional (such as PBE and B3LYP) for the molecules with long flexible chains.

Frontier molecular orbitals (HOMO and LUMO) were found to be extremely valuable in the interpretation of relevant chemical reactivity. The capacity of a molecule to donate electrons is strongly linked to the HOMO. HOMO also determines the spatial distribution of valence electron mainly participating in the formation of chemical bonds, and LUMO is well correlated with the capacity of a molecule to accept electrons.

As shown in Table 2, the HOMO energies of both $\mathrm{TTP}^{+}$and $\mathrm{DTA}^{+}$cations are very low, leading to relatively weak electron-donating ability. Figure 4 presents the HOMO and LUMO of (i) DTA+ and (ii) $\mathrm{TTP}^{+}$at wB97XD/Def2-TZVP level. It was demonstrated that the HOMO is mainly distributed in the dodecyl chain, LUMO is mostly located at the "head" atoms $\mathrm{N}^{+}\left(\mathrm{CH}_{3}\right)_{3}$ for DTA ${ }^{+}$. In the case of $\mathrm{TTP}^{+}$, the result is similar. Its HOMO is mainly distributed in its tetradecyl chain, its LUMO is mostly located at the "head" atoms $\mathrm{P}^{+}\left(\mathrm{C}_{4} \mathrm{H}_{9}\right)$. Due to the detailed component analysis of molecular orbitals, it is found that the HOMO is mainly constituted by $\mathrm{P}_{\mathrm{x}}$ or $\mathrm{P}_{\mathrm{z}}$ orbits of carbon atoms in long alkyl chain at the end, which have been fully occupied by valence electrons and have no chance to offer P-orbit electrons to other atoms to form a chemical bond. The LUMO of TTP ${ }^{+}$or $\mathrm{DTA}^{+}$is mainly composed of s orbits of carbon atoms (not the valence orbits) in the tributyl or trimethyl group, 
respectively, which indicates that LUMO cannot accept feedback electrons from the surface atoms (oxygen, iron, silicon) of magnetite and quartz to form chemical bonds. It could be expected that the interaction between the flotation reagents $\left(\mathrm{TTP}^{+}\right.$and $\left.\mathrm{DTA}^{+}\right)$and mineral surfaces should be attributed to the electrostatic force. Thus, the charge population in $\mathrm{DTP}^{+}$and $\mathrm{TTP}^{+}$will strongly influence their flotation performance.

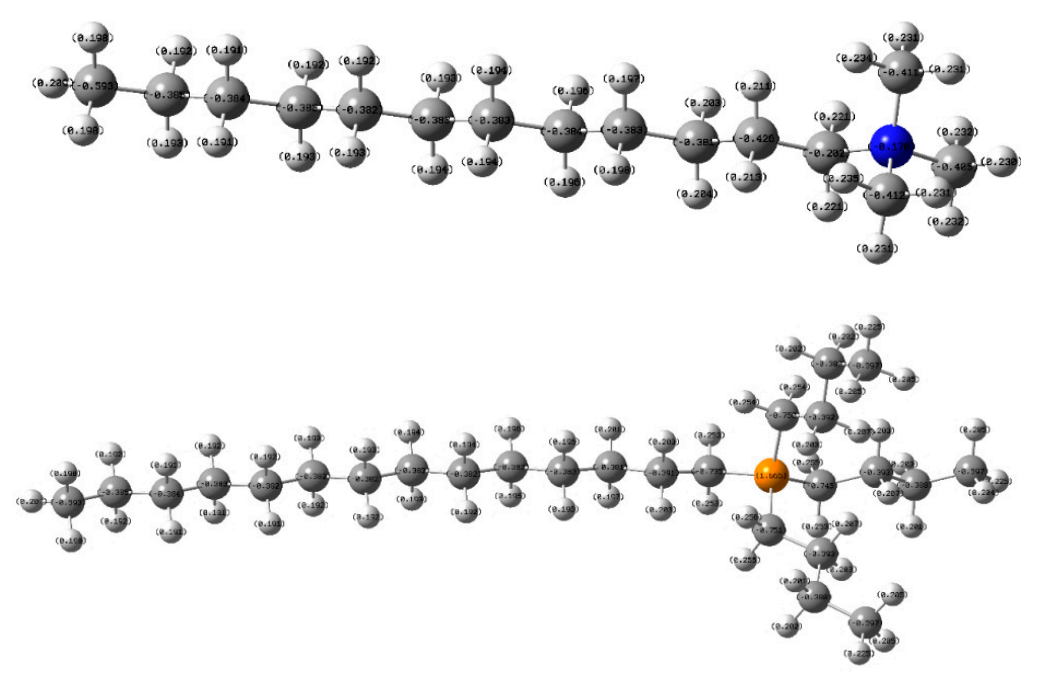

Figure 3. The optimized structures of DTA ${ }^{+}$(Top) and TTP ${ }^{+}$(Bottom) at wB97XD/Def2-TZVP level (Blue-N, Yellow-P, Gray-C, and White-H).

Table 2. The frontier molecular orbital eigenvalues of the $\mathrm{DTA}^{+}$and $\mathrm{TTP}^{+}$collectors at wB97XD/Def2TZVP level, unit is in $\mathrm{Kcal} / \mathrm{mol}$.

\begin{tabular}{ccccc}
\hline \multirow{2}{*}{ Basis Set } & \multicolumn{2}{c}{ DTA $^{+}$} & \multicolumn{2}{c}{ TTP $^{+}$} \\
\cline { 2 - 5 } & HOMO & LUMO & HOMO & LUMO \\
\hline Def2-TZVP & -272.2 & -37.2 & -262.7 & -23.8 \\
Def2-SVP & -273.9 & -30.3 & -265.3 & -19.9 \\
\hline
\end{tabular}

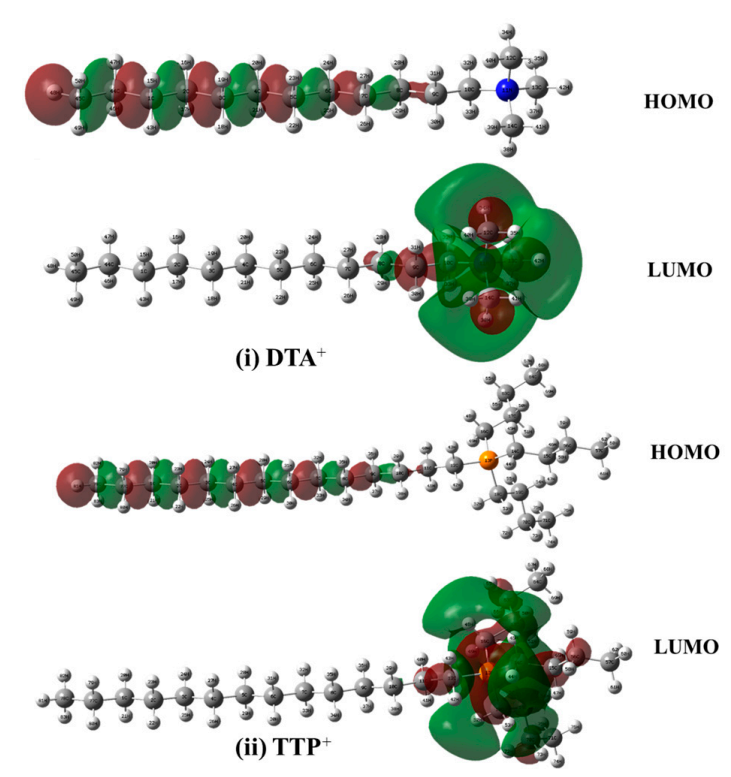

Figure 4. The diagrams of highest occupied molecular orbital (HOMO) and lowest unoccupied molecular orbital (LOMO) of (i) $\mathrm{DTA}^{+}$and (ii) $\mathrm{TTP}^{+}$at wB97XD/Def2-TZVP level. 
In this study, two commonly used Mulliken and NPA charges of the $\mathrm{N}$ atom, $\mathrm{N}^{+}\left(\mathrm{CH}_{3}\right)_{3}$ group in $\mathrm{DTA}^{+}$and $\mathrm{P}$ atom, $\mathrm{P}^{+}\left(\mathrm{C}_{4} \mathrm{H}_{9}\right)_{3}$ group in $\mathrm{TTP}^{+}$are obtained with wB97XD/Def2-TZVP and wB97XD/Def2-SVP methods, respectively.

As shown in Table 3, Mulliken charge are more sensitive to the basis set than NPA charge. Especially, the Mulliken charges of nitrogen atom with different basis sets are qualitatively inconsistent. It is value of -0.399 for small basis set Def2-SVP, but 0.075 for big basis set Def2-TZVP. Fortunately, Mulliken population method could give close charges for group $\left(\mathrm{N}^{+}\left(\mathrm{CH}_{3}\right)_{3}\right)$ or $\left(\mathrm{P}^{+}\left(\mathrm{CH}_{3}\right)_{3}\right)$ with different basis set. However, NPA method could give consistent charges for a given atom $(\mathrm{N}$ or $\mathrm{P})$ or a given group $\left(\mathrm{N}^{+}\left(\mathrm{CH}_{3}\right)_{3}\right.$ or $\left.\mathrm{P}^{+}\left(\mathrm{CH}_{3}\right)_{3}\right)$ with different basis set. Particularly, it could obtain almost the same charges for group $\left(\mathrm{N}^{+}\left(\mathrm{CH}_{3}\right)_{3}\right)$ or $\left(\mathrm{P}^{+}\left(\mathrm{CH}_{3}\right)_{3}\right)$ with different basis set. Thus, NPA charge is a better parameter to assess the possible performance of $\mathrm{TTP}^{+}$and $\mathrm{DTA}^{+}$in flotation. It was illustrated that that both the key atom and the active group of $\mathrm{TTP}^{+}$significantly take more positive charges in comparison to $\mathrm{DTA}^{+}$, which means that $\mathrm{TTP}^{+}$will have a stronger interaction with the quartz surface than $\mathrm{DTA}^{+}$. In addition, as shown in Figure 5, $\mathrm{TTP}^{+}$shows a similar electrostatic potential (electronic density) distribution with $\mathrm{DTA}^{+}$, but the positive electrostatic potential in $\mathrm{TTP}^{+}$are more concentrated on the active group $\left(\mathrm{P}^{+}\left(\mathrm{C}_{4} \mathrm{H}_{9}\right)_{3}\right)$, which implies that $\mathrm{TTP}^{+}$could become a promising candidate for cationic flotation practice like DTA ${ }^{+}$, even better than $\mathrm{DTA}^{+}$.

Table 3. The Mulliken and NPA charges of the $\mathrm{N}$ atom, $\mathrm{N}^{+}\left(\mathrm{CH}_{3}\right)_{3}$ group in $\mathrm{DTA}^{+}$and $\mathrm{P}$ atom, $\mathrm{P}^{+}\left(\mathrm{C}_{4} \mathrm{H}_{9}\right)_{3}$ group in TTP ${ }^{+}$with wB97XD/Def2-TZVP and wB97XD/Def2-SVP methods, respectively.

\begin{tabular}{ccccc}
\hline \multirow{2}{*}{ Basis Set } & \multicolumn{2}{c}{ DTA $^{+}$} & \multicolumn{2}{c}{ TTP $^{+}$} \\
\cline { 2 - 5 } & Mulliken & NPA & Mulliken & NPA \\
\hline Def2-TZVP & 0.075 & -0.170 & 0.512 & 1.665 \\
Def2-SVP & -0.399 & -0.369 & 0.326 & 1.581 \\
\hline Group $\left(\mathrm{N}^{+}\left(\mathrm{CH}_{3}\right)_{3}\right)$ & Group $\left(\mathrm{P}^{+}\left(\mathrm{C}_{4} \mathrm{H}_{9}\right)\right)$ \\
\hline Def2-TZVP & 0.800 & 0.690 & 0.865 & 1.158 \\
\hline & 0.650 & 0.650 & 0.816 & 1.14 \\
\hline & & & & \\
\hline
\end{tabular}

Figure 5. Diagrams of isostatic potential (electronic density) distribution of $\mathrm{DTA}^{+}$(Top) and $\mathrm{TTP}^{+}$ (Bottom) at wB97XD/Def2-TZVP level.

Finally, it should be emphasized that the experimental studies in the next section will show that the IEP (isoelectric point) of quartz is 2.0 , and the surface of quartz is negatively charged over the $\mathrm{pH}$ range 2-12. As the cationic collector, once TTPC or DTAC was introduced into flotation pulp, 
their cations $\left(\mathrm{TTP}^{+}\right.$or $\left.\mathrm{DTA}^{+}\right)$might be electrostatically attracted to the negatively charged positions on the quartz surface. Since the electrostatic effect is generally directly proportional to the grouping charge of collector [42,43], it can be predicted that a higher flotation recovery will be observed when using the TTPC as a collector.

\subsection{Zeta Potential Measurements}

Quaternary phosphonium salts and quaternary ammonium salts have similar structures. The electrostatic adsorption mechanisms of quaternary ammonium salts have been widely reported by various researchers $[44,45]$. To illustrate the effect of the adsorption of TTPC on the electrokinetic behavior of quartz surface, the zeta potential of quartz and magnetite as a function of $\mathrm{pH}$ values were measured in the presence and absence of TTPC or DTAC. As shown in Figure 5, the isoelectric point (IEP) of quartz and magnetite are 2.0 and 5.5, respectively, which is consistent with those previously reported $[5,13,46]$. As demonstrated in Figure 6 a, the zeta potential of quartz shows a pronounced positive shift in the presence of TTPC or DTAC, and the isoelectric point (IEP) of quartz and magnetite are increased to 4.4 and 7.4, respectively, in the presence of DTAC. It indicates that the cationic surfaces have been adsorbed onto quartz through electrostatic force. Particularly, the Zeta potential of TTPC-treated quartz is much higher than that of DTAC treated quartz for a given $\mathrm{pH}$ value, implying that there are more positive charges on the quartz surface in the presence of cationic species $\mathrm{TTP}^{+}$ than that in the presence of DTA ${ }^{+}$. Figure $4 \mathrm{~b}$ shows that the zeta potential of magnetite also exhibits a positive shift when TTPC or DTAC was added, but the shift is relatively smaller, suggesting that the adsorption amount of cationic surfactants is much less on the magnetite surface. It could be predicted that both cationic surfactants will possess a good selectivity in iron ores reverse flotation, based on the significant differences between Figure $6 a, b$.
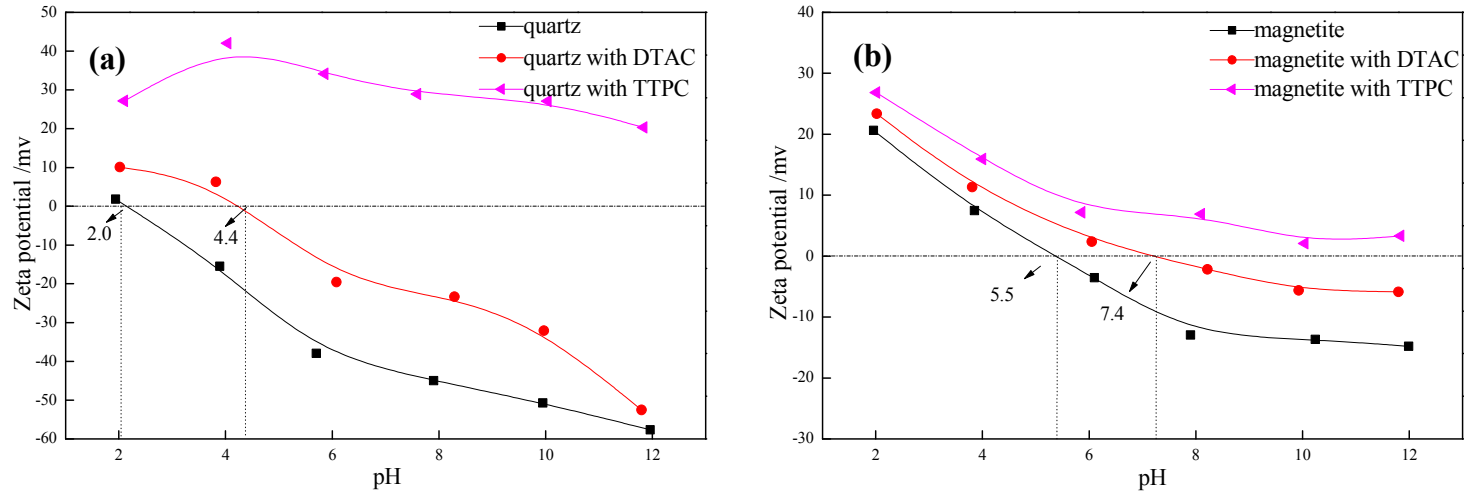

Figure 6. Effect of the addition of different reagents on the zeta potentials of quartz (a) and magnetite (b). The concentration of DTAC or TTPC is $2.0 \times 10^{-5} \mathrm{~mol} / \mathrm{L}$.

\subsection{Adsorption Isotherm Measurements}

Isotherm, defined as the amount of adsorbate on a surface as a function of its concentration (for liquid) or pressure (for gas) at constant temperature, is usually adopted to describe adsorption behavior [47,48]. Adsorption isotherms are useful to investigate the characteristics of adsorbates at the liquid/solid interface [49,50]. Figure 7 presents the adsorption isotherm of TTPC and DTAC on quartz surface. It can be seen that as the increase of TTPC concentration from $5 \times 10^{-7}$ to $1 \times 10^{-2} \mathrm{~mol} / \mathrm{L}$, the adsorption amount of TTPC on quartz surface increases rapidly until to the concentration of $1 \times 10^{-4} \mathrm{~mol} / \mathrm{L}$, then increases moderately until to the concentration of $1 \times 10^{-3} \mathrm{~mol} / \mathrm{L}$. In the range of $1 \times 10^{-3}$ to $1 \times 10^{-2} \mathrm{~mol} / \mathrm{L}$, the increase of the adsorption amount is extremely slow; when the concentration of TTPC is greater than $1 \times 10^{-2} \mathrm{~mol} / \mathrm{L}$, the adsorption amount of TTPC will no longer change. The adsorption behavior of DTAC is analogous to TTPC, but with much less adsorption amount for a given concentration in the range of $1 \times 10^{-5}$ to $1 \times 10^{-3} \mathrm{~mol} / \mathrm{L}$. The adsorption 
amount is closely related to the collecting capability: more adsorption amount usually means stronger collecting capability.

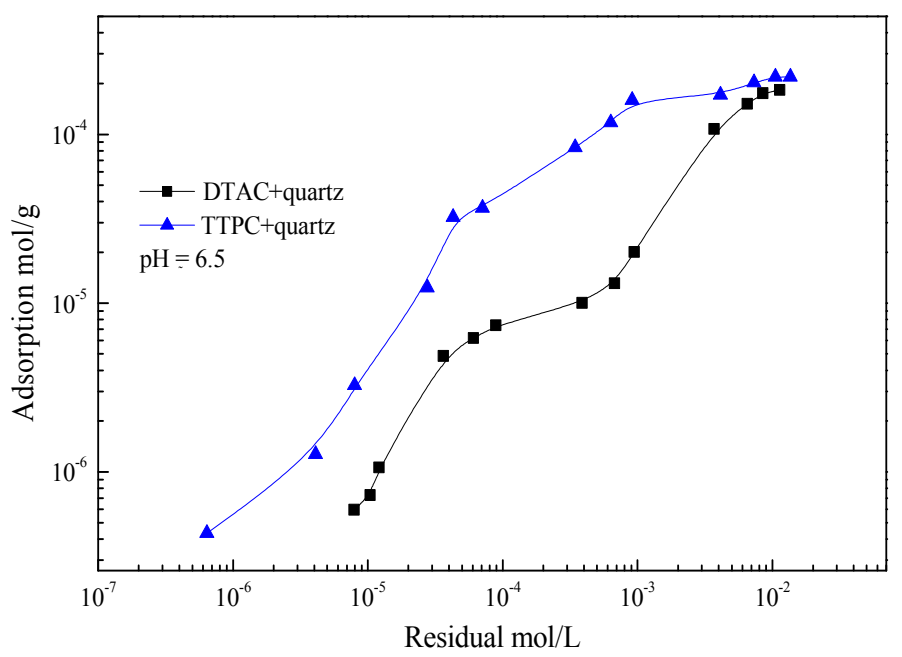

Figure 7. Adsorption isotherm of tributyltetradecyl-phosphonium chloride (TTPC) and dodecyl triethyl ammonium chloride (DTAC) on quartz surface.

\subsection{Micro-Flotation Tests}

The DFT calculations and Zeta potential measurements had shown that active part $\left(\mathrm{P}^{+}\left(\mathrm{C}_{4} \mathrm{H}_{9}\right)_{3}\right)$ of $\mathrm{TTP}^{+}$takes much more positive charges than that $\left(\mathrm{N}^{+}\left(\mathrm{CH}_{3}\right)_{3}\right)$ of $\mathrm{DTA}^{+}$. Thus, it will result in stronger electrostatic attraction and more adsorption amount of $\mathrm{TTP}^{+}$on quartz. These predictions need to be further verified by the flotation experiments.

Single-mineral flotation of quartz and magnetite was conducted as a function of $\mathrm{pH}$ with $2 \times 10^{-5} \mathrm{~mol} / \mathrm{L}$ TTPC or DTAC as collectors. As shown in Figure 8a, the recovery of quartz in presence of TTPC or DTAC goes up as $\mathrm{pH}$ increases. In acidic $\mathrm{pH}$ range $2-6$, the recovery of quartz rises rapidly as the $\mathrm{pH}$ increases. In neutral and alkaline $\mathrm{pH}$ range, the pulp $\mathrm{pH}$ has a subtle effect on the quartz recovery. Furthermore, at $\mathrm{pH}$ value about 6.5 and collector concentration $2 \times 10^{-5} \mathrm{~mol} / \mathrm{L}$, the flotation recovery of quartz is about $95 \%$ with TTPC, whereas it is only about $60 \%$ with DTAC. If we consider using the same dosage of collectors in mass, since the molecular mass of TTPC (435.15) is 1.65 times more than that of DTAC (263.89), $3.3 \times 10^{-5} \mathrm{~mol} / \mathrm{L}$ DTAC will be equal to $2 \times 10^{-5} \mathrm{~mol} / \mathrm{L}$ TTPC in mass. The corresponding flotation recovery of quartz is about $88 \%$ with $3.3 \times 10^{-5} \mathrm{~mol} / \mathrm{L}$ DTAC from Figure $8 \mathrm{~b}$. It suggests that TTPC has a stronger collecting power than DTAC.
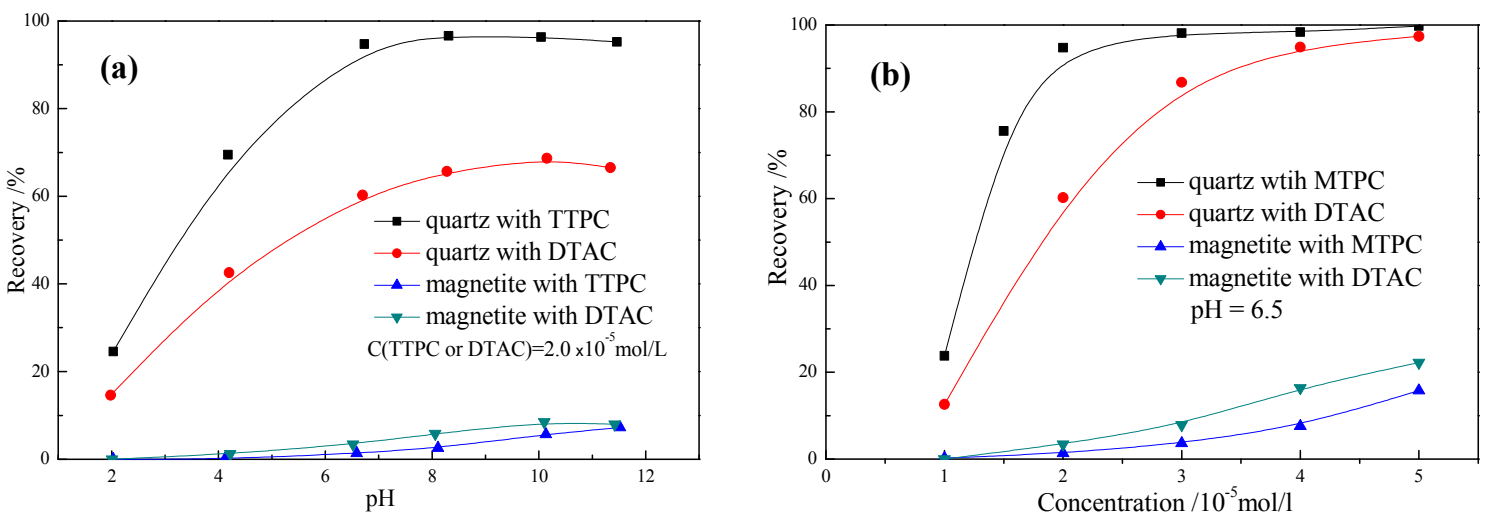

Figure 8. Flotation results of quartz and magnetite in the presence of TTPC and DTAC surfactants as a function of (a) $\mathrm{pH}$ and (b) the collector concentration. 
On the other hand, the recovery of magnetite increases slowly over the entire $\mathrm{pH}$ range 2-12. The optimal magnetite recovery is less than $10 \%$ in the presence of TTPC or DTAC. Therefore, the appropriate $\mathrm{pH}$ value ranges from 6 to 12 for flotation separation of quartz from magnetite.

The effect of collector concentration of TTPC or DTAC on the quartz and magnetite flotation at $\mathrm{pH} 6.5$ is presented in Figure 8b. It is observed that the quartz recovery goes up with the increase of surfactant concentration. Particularly, for a given collector concentration of $2 \times 10^{-5} \mathrm{~mol} / \mathrm{L}$, the flotation recovery of quartz is $94.74 \%$ with TTPC, whereas it is only $60.23 \%$ with DTAC, which also implies that TTPC has a better collecting ability than DTAC in this case. On the other hand, magnetite has relatively very low recoveries in the entire concentration range. Particularly, when the collector concentration is below $2 \times 10^{-5} \mathrm{~mol} / \mathrm{L}$, there is almost no recovery of magnetite. Thus, the recommended collector concentration for flotation separation of quartz from magnetite is about $2 \times 10^{-5} \mathrm{~mol} / \mathrm{L}$.

The results based on the micro-flotation indicate that two cationic collectors show excellent selectivity for quartz against magnetite under pH 6-12 and $2 \times 10^{-5} \mathrm{~mol} / \mathrm{L}$ collector concentration. However, TTPC performs significantly better than DTAC under the same condition.

As the surface properties of minerals are affected greatly by each component in the solution, flotation tests of mixed minerals were carried out to further investigate the flotation performance of TTPC and DTAC. The flotation separation of mixtures of quartz and magnetite was conducted at pH 6.5-7.0 using $2 \times 10^{-5} \mathrm{~mol} / \mathrm{L}$ TTPC and DTAC as collector, respectively. The results about the separation of the mixtures are displayed in Table 4.

Table 4. The separation results of mixtures (wt \%).

\begin{tabular}{ccccccc}
\hline \multirow{2}{*}{ Collector } & \multirow{2}{*}{ Product } & \multirow{2}{*}{ Weight } & \multicolumn{2}{c}{ Grade } & \multicolumn{2}{c}{ Recovery } \\
\cline { 4 - 7 } & & & Fe & $\mathbf{S i O}_{\mathbf{2}}$ & $\mathbf{F e}$ & $\mathbf{S i O}_{\mathbf{2}}$ \\
\hline \multirow{3}{*}{ DTAC } & Concentrate & 80.27 & 65.41 & 7.41 & 95.88 & 25.57 \\
& Tailings & 19.73 & 11.43 & 87.74 & 4.12 & 74.43 \\
& Feeds & 100.00 & 54.76 & 23.26 & 100.00 & 100.00 \\
\hline \multirow{3}{*}{ TTPC } & Concentrate & 78.34 & 67.83 & 5.38 & 97.03 & 18.35 \\
& Tailings & 21.66 & 7.49 & 91.92 & 2.97 & 81.65 \\
& Feeds & 100.00 & 54.76 & 23.26 & 100.00 & 100.00 \\
\hline
\end{tabular}

The results in Table 4 show that in the magnetite concentrates obtained, the grade of $\mathrm{Fe}$ and $\mathrm{SiO}_{2}$ are $67.83 \%$ and $5.38 \%$, respectively, in the presence of TTPC. However, a magnetite concentrate grade of $65.41 \%$ Fe could be obtained using DTAC as a collector. It indicates TTPC possessed better flotation selectivity, compared with traditional collector DTAC. The recovery of Fe is $97.03 \%$ and $95.88 \%$ in the presence of TTPC and DTAC, respectively. Micro-flotation tests suggest that TTPC might be a more efficient collector than DTAC in the reverse cationic flotation separation of quartz from magnetite.

\subsection{Bench-Scale Flotation}

It is well understood that the competitive adsorption of reagents on the different minerals could not be well demonstrated by the pure mineral flotation tests [51]. The reagent might be very effective onto pure minerals, but the application of this reagent might fail under the condition of more complicated separation system, such as flotation separation of iron ores. Therefore, bench-scale tests were conducted on the reverse flotation separation of quartz from magnetite with TTPC and DTAC as collectors to verify the flotation ability of TTPC.

The flowsheet of tests was presented in Figure 2 and the results were summarized in Table 5. The results showed that the magnetite concentrates with $66.42 \% \mathrm{Fe}$ and $4.21 \% \mathrm{SiO}_{2}$ could be obtained with TTPC collector at a natural $\mathrm{pH}$, and the flotation recovery of $\mathrm{Fe}$ is $95.63 \%$. While the grade and recovery of magnetite concentrates, with DTAC collector, are $65.34 \%$ Fe and $93.20 \%$, respectively.

The results of micro-flotation and bench-scale flotation experiments both demonstrate TTPC exhibit a superior flotation ability to separate quartz from magnetite. 
Table 5. Reverse cationic flotation results of iron ore with TTPC and DTAC as collectors at a natural $\mathrm{pH}(6.5-7.0)$ (wt \%).

\begin{tabular}{ccccccc}
\hline \multirow{2}{*}{ Collector } & \multirow{2}{*}{ Product } & \multirow{2}{*}{ Weight } & \multicolumn{2}{c}{ Grade } & \multicolumn{2}{c}{ Recovery } \\
\cline { 4 - 7 } & & & Fe & $\mathbf{S i O}_{2}$ & Fe & SiO $_{2}$ \\
\hline \multirow{3}{*}{ DTAC } & Concentrate & 77.65 & 65.34 & 5.62 & 93.20 & 23.40 \\
& Tailings & 22.35 & 16.57 & 63.92 & 6.80 & 76.60 \\
& Feeds & 100.00 & 54.44 & 18.65 & 100.00 & 100.00 \\
\hline \multirow{2}{*}{ TTPC } & Concentrate & 78.63 & 66.42 & 4.21 & 95.63 & 17.71 \\
& Tailings & 21.37 & 11.16 & 71.97 & 4.37 & 82.29 \\
& Feeds & 100.00 & 54.61 & 18.69 & 100.00 & 100.00 \\
\hline
\end{tabular}

\subsection{Adsorption Mechanism}

Based on the above discussions from prediction and experimental verification, it can be concluded that TTPC exhibits an excellent collecting capability and efficient selectivity in the reverse flotation separation of quartz from iron ore, TTPC might be a promising collector for iron ore flotation. To better understand the adsorption behaviors of TTPC and DTAC on quartz surface, adsorption isotherms of TTPC and DTAC would be discussed in considerable detail. As shown in Figure 9a, adsorption isotherms of TTPC and DTAC similarly experience 4 regions until the adsorption reaches the maximum, which is in good agreement with the reverse orientation adsorption model proposed by Somasundaran and Fuerstenau $[32,33,52,53]$. The schematic model of the adsorbed surfactant at the quartz/water interface in the four regions [54] has also been proposed and illustrated in Figure 9b.

According to the absorption model of Somasundaran and Fuerstenau as shown in Figure 9b, in region 1, surfactants initially adsorb on mineral surface by electrostatic force as individual ions. In region 2, with the increase in the coverage of surfactant on mineral surface, the steric hindrance gradually appears. The adsorbed surfactants associate into hemimicelle, in which the surfactants are oriented with their charged head groups toward the mineral surface, while their hydrocarbon chains protrude into the aqueous phase, thus resulting in hydrophobic layer on the surface. In region 3 , with the further adsorption of surfactants, the exposed mineral surface has been fully covered and neutralized by the oppositely charged surfactant, the molecules of surfactants can no longer be further absorbed on the mineral surface by electrostatic attraction and are adsorbed by hydrophobic force in an opposite orientation. The bilayer adsorption started. Finally, in region 4, the adsorbed layer on mineral surface presents the structure of a bilayer, thus further increase of reagent concentration has almost no influence on the adsorption.

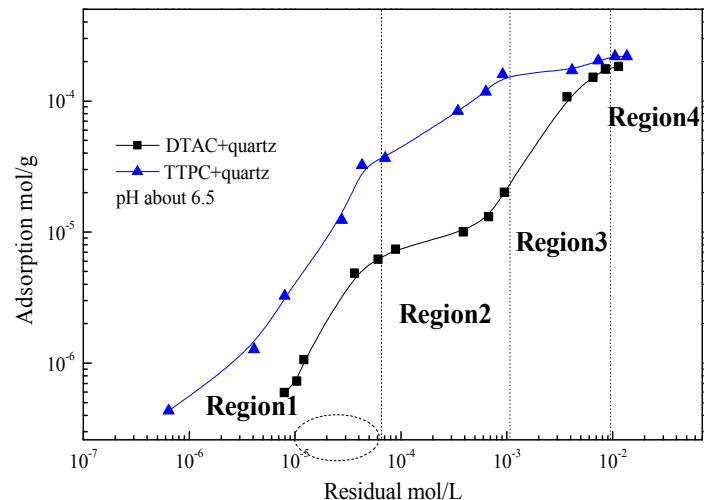

(a)

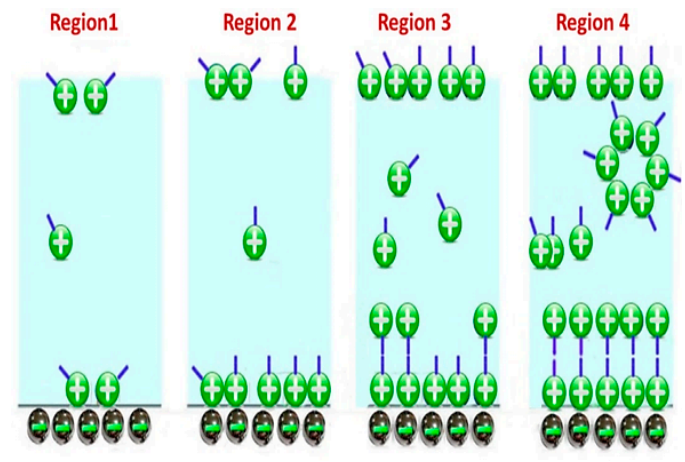

(b)

Figure 9. (a) Adsorption isotherm of TTPC and DTAC on quartz surface; and (b) the proposed adsorption models of TTPC and DTAC at the quartz/water interface for different regions in the adsorption isotherms of (a). 
Furthermore, to illustrate the correlation of the adsorption behavior with the flotation recovery, the adsorption isotherm of the region $1[32,33]$ were replotted in Figure 10 with the flotation recovery. It can be observed that there is a clearly positive correlation between flotation recovery and adsorption amount. As shown in Figure 10, at the neutral pH, as the increase of adsorption amount of DTAC and TTPC, the flotation recovery of quartz significantly goes up. Both DTAC and TTPC are highly effective to the quartz flotation. The flotation recovery of quartz almost reaches $100 \%$ when the initially adopted concentration of TTPC or DTAC is $2 \times 10^{-5}$ or $4 \times 10^{-5} \mathrm{~mol} / \mathrm{L}$, respectively. Obviously, the dosage range of TTPC and DTAC belongs to the region 1 of the adsorption isotherm, where surfactant molecules could rapidly absorb on mineral surface by electrostatic attraction. In the other words, the electrostatic forces between surfactant and quartz surface determine the adsorption amount of surfactants, affecting directly the flotation behaviors of quartz. Therefore, more positive charges of $\mathrm{TTP}^{+}$can be expected to demonstrate a stronger electrostatic interaction of $\mathrm{TTP}^{+}$with negatively charged quartz surface, which is of great advantage to form an improved hydrophobic surface and results in excellent flotation ability.

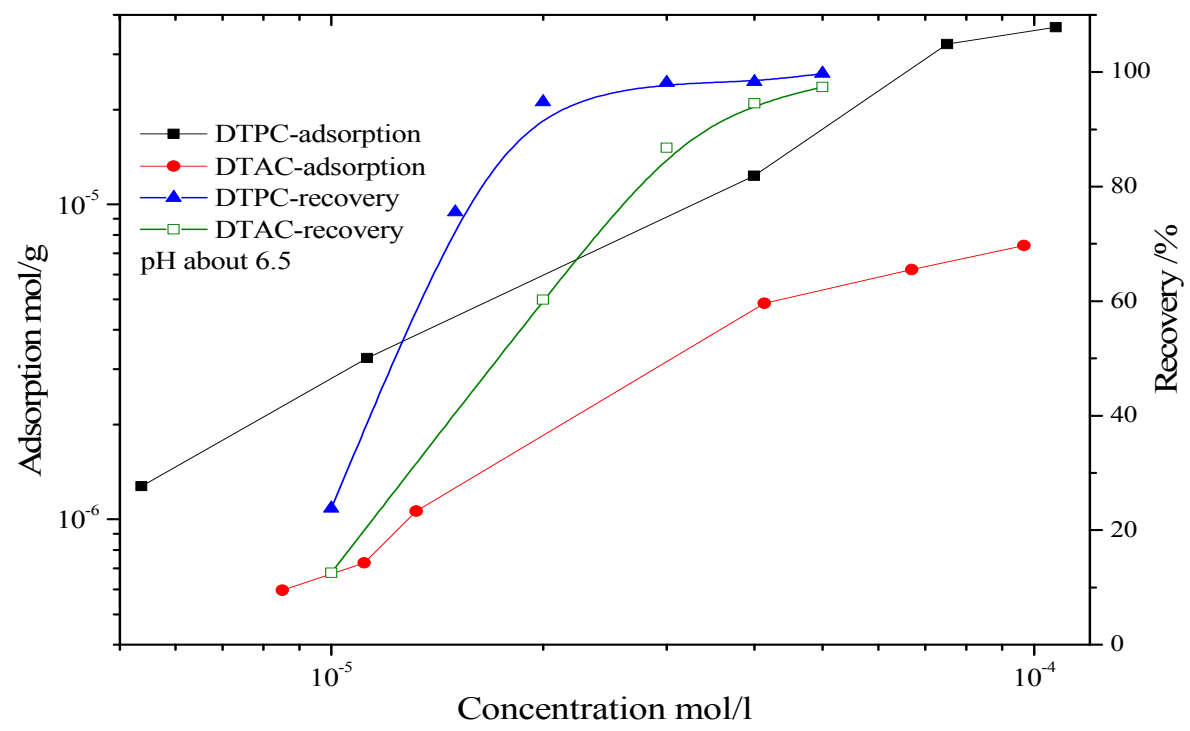

Figure 10. The correlation of the valuable mineral flotation recovery and the adsorption amount of TTPC or DTAC with respect to collector concentration.

In this work, it should be mentioned that substituent alkyl groups in TTPC and DTAC are not the same, but they are very close: there is only a discrepancy of two carbon atoms in the long alkyl chain and three carbon atoms in the three-short alkyl chain. In addition, the critical topological structures of TTPC and DTAC are very similar: both belong to quaternary salts, represented as $\left[\mathrm{XR}_{4}\right]^{+} \mathrm{Y}^{-}$(R being an alkyl group or an aryl group, $\mathrm{X}$ being $\mathrm{N}$ or $\mathrm{P}$ atom, and $\mathrm{Y}^{-}$being halide ion) [55].

\section{Conclusions}

In the present work, tributyltetradecyl-phosphonium chloride (TTPC) has been first predicated and introduced to be a novel and efficient cationic surfactant for cationic reverse flotation separation of quartz from magnetite. Based on the computational and experimental results, the following conclusions are drawn:

(1) TTPC prefers to physically adsorb on the objective mineral surface by electrostatic force, like the DTAC. Furthermore, the calculation of NPA charge indicates that active part $\left(\mathrm{P}^{+}\left(\mathrm{C}_{4} \mathrm{H}_{9}\right)\right)$ of $\mathrm{TTP}^{+}$ takes much more positive charges than that $\left(\mathrm{N}^{+}\left(\mathrm{CH}_{3}\right)_{3}\right)$ of DTA ${ }^{+}$, meaning that TTPC may be a promising collector like or even better than DTAC; 
(2) Zeta potential measurements show that the potential of TTPC or DTAC adsorbed quartz surface is much higher than the untreated quartz surface. Particularly, the potential of the TTPC adsorbed quartz surface is significantly more positive than that of the DTAC adsorbed quartz surface, which is in good agreement with the computational results;

(3) Adsorption tests illustrate that the adsorption amount of TTPC is much more than that of DTAC at low concentration, and the flotation experiments confirm that the adsorption amount of TTPC or DTAC is positively correlated to the flotation recovery, suggesting that TTPC is a potential candidate collector for iron ore flotation;

(4) Micro-flotation and Bench-scale flotation results further verify that TTPC presents stronger collecting power and much better selectivity in the separation of quartz from magnetite in comparison with the conventional collector DTA.

Furthermore, it should be emphasized that the research about the effect of carbon chain length on the flotation performance is ongoing in our laboratory. This work may represent a good example to discover a potential candidate collector by analogy with known excellent collector based on reasonable prediction.

Acknowledgments: The present work is financially supported the Natural Science Foundation of China (51504290), the National Science and Technology Support Program (2015BAB19B01), the Innovation-driven Program of Central South University of China (2015CX005), the National 111 Project (B14034), the Startup Fund of Central South University for Young Teachers (502044001), and the Collaborative Innovation Center for Clean and Efficient Utilization of Strategic Metal Mineral Resources. This work was carried out in part using hardware and/or software provided by the High-Performance Computing Centers of Central South University and Nanjing University. The staff from the Supercomputing Center and High-Performance Computing Centers and the engineers from Beijing Paratera Technology Co., Ltd. provided effective support and made the computation smoothly during the course. Sincere gratitude must be given to them.

Author Contributions: Chenyang Zhang and Wei Sun conceived and designed the experiments and calculations; Pan Chen performed the experiments; Yuehua $\mathrm{Hu}$ and Zhiyong Gao analyzed the experimental data and modified the paper; Yuehua Hu investigated literatures; Jihua Zhai performed flotation tests and adsorption tests; Chenyang Zhang and Dong Fang performed the DFT calculations and analyzed computational results; and Tong Yue drew the figures; Pan Chen and Chenyang Zhang wrote the paper.

Conflicts of Interest: The authors declare no conflict of interest. The founding sponsors had no role in the design of the study; in the collection, analyses, or interpretation of data; in the writing of the manuscript, and in the decision to publish the results.

\section{References}

1. Filippov, L.O.; Severov, V.V.; Filippova, I.V. An overview of the beneficiation of iron ores via reverse cationic flotation. Int. J. Miner. Process. 2014, 127, 62-69. [CrossRef]

2. Clemmer, J.B. Flotation of iron ores. In Proceedings of the 8th Annual Mining Symposium, Duluth, MN, USA, January 1947.

3. Araujo, A.C.; Viana, P.R.M.; Peres, A.E.C. Reagents in iron ores flotation. Miner. Eng. 2005, 18, 219-224. [CrossRef]

4. Weng, X.; Mei, G.; Zhao, T.; Zhu, Y. Utilization of novel ester-containing quaternary ammonium surfactant as cationic collector for iron ore flotation. Sep. Purif. Technol. 2013, 103, 187-194. [CrossRef]

5. Filippov, L.O.; Filippova, I.V.; Severov, V.V. The use of collectors mixture in the reverse cationic flotation of magnetite ore: The role of Fe-bearing silicates. Miner. Eng. 2010, 23, 91-98. [CrossRef]

6. Batisteli, G.M.B.; Peres, A.E.C. Residual amine in iron ore flotation. Miner. Eng. 2008, 21, 873-876. [CrossRef]

7. Uwadiale, G.G.O.O. Flotation of iron oxides and quartz-A review. Miner. Process. Extr. Metall. Rev. 1992, 11, 129-161. [CrossRef]

8. Wang, Y.; Ren, J. The flotation of quartz from iron minerals with a combined quaternary ammonium salt. Int. J. Miner. Process. 2005, 77, 116-122.

9. Vieira, A.M.; Peres, A.E.C. The effect of amine type, $\mathrm{pH}$, and size range in the flotation of quartz. Miner. Eng. 2007, 20, 1008-1013. [CrossRef]

10. Huang, Z.; Hong, Z.; Shuai, W.; Xia, L.; Zou, W.; Liu, G. Investigations on reverse cationic flotation of iron ore by using a Gemini surfactant: Ethane-1,2-bis(dimethyl-dodecyl-ammonium bromide). Chem. Eng. J. 2014, 257, 218-228. [CrossRef] 
11. Kar, B.; Sahoo, H.; Rath, S.S.; Das, B. Investigations on different starches as depressants for iron ore flotation. Miner. Eng. 2013, 49, 1-6. [CrossRef]

12. Turrer, H.D.G.; Peres, A.E.C. Investigation on alternative depressants for iron ore flotation. Miner. Eng. 2010, 23, 1066-1069. [CrossRef]

13. Lima, N.P.; Valadão, G.E.S.; Peres, A.E.C. Effect of amine and starch dosages on the reverse cationic flotation of an iron ore. Miner. Eng. 2013, 45, 180-184. [CrossRef]

14. Pavlovic, S.; Brandao, P.R.G. Adsorption of starch, amylose, amylopectin and glucose monomer and their effect on the flotation of hematite and quartz. Miner. Eng. 2003, 16, 1117-1122. [CrossRef]

15. Montes-Sotomayor, S.; Houot, R.; Kongolo, M. Flotation of silicated gangue iron ores: Mechanism and effect of starch. Miner. Eng. 1998, 11, 71-76. [CrossRef]

16. Ge, H.; Wang, Y.; Li, C.; Chen, N.; Xie, Y.; Xu, M.; He, Y.; Gu, X.; Wu, R.; Gu, Q. Molecular dynamics-based virtual screening: Accelerating the drug discovery process by high-performance computing. J. Chem. Inf. Model. 2013, 53, 2757-2764. [CrossRef] [PubMed]

17. Brédas, J.L.; Persson, K.; Seshadri, R. Computational design of functional materials. Chem. Mater. 2017, 29, 2399-2401. [CrossRef]

18. Zhang, Y.; Miller, G.J.; Fokwa, B.P.T. Computational design of rare-earth-free magnets with the $\mathrm{Ti}_{3} \mathrm{Co}_{5} \mathrm{~B}_{2}$-type structure. Chem. Mater. 2015, 29, 2535-2541. [CrossRef]

19. Curtarolo, S.; Hart, G.L.; Nardelli, M.B.; Mingo, N.; Sanvito, S.; Levy, O. The high-throughput highway to computational materials design. Nat. Mater. 2013, 12, 191-201. [CrossRef] [PubMed]

20. Hu, Y.H.; He, J.Y.; Zhang, C.H.; Zhang, C.Y.; Sun, W.; Zhao, D.B.; Chen, P.; Han, H.S.; Gao, Z.Y.; Liu, R.Q.; et al. Insights into the activation mechanism of calcium ions on the sericite surface: A combined experimental and computational study. Appl. Surf. Sci. 2018, 427, 162-168. [CrossRef]

21. Pradip; Rai, B. Molecular modeling and rational design of flotation reagents. Int. J. Miner. Process. 2003, 72, 95-110. [CrossRef]

22. Liu, G.; Yang, X.; Zhong, H. Molecular design of flotation collectors: A recent progress. Adv. Colloid Interface Sci. 2017, 246, 181-195. [CrossRef] [PubMed]

23. Wu, T.; Xie, A.G.; Tan, S.Z.; Cai, X. Antimicrobial effects of quaternary phosphonium salt intercalated clay minerals on Escherichia coli and Staphylococci aureus. Colloids Surf. B Biointerfaces 2011, 86, 232-236. [CrossRef] [PubMed]

24. Wang, M.L.; Liu, B.L.; Lin, S.J. Synthesis of an active quaternary phosphonium salt and its application to the Wittig reaction: Kinetic study. J. Chin. Inst. Chem. Eng. 2007, 38, 451-459. [CrossRef]

25. Li, C.; Liu, Y.; Zeng, Q.Y.; Ao, N.J. Preparation and antimicrobial activity of quaternary phosphonium modified epoxidized natural rubber. Mater. Lett. 2013, 93, 145-148. [CrossRef]

26. Rodrigues, O.M.S.; Peres, A.E.C.; Martins, A.H.; Pereira, C.A. Kaolinite and hematite flotation separation using etheramine and ammonium quaternary salts. Miner. Eng. 2013, 40, 12-15. [CrossRef]

27. Zhai, J.; Chen, P.; Sun, W.; Hu, Y.H.; Yue, T.; Lai, X.S. Evaluation of quaternary phosphonium salt as the collector in bauxite reverse flotation. J. Environ. Chem. Eng. 2017, 5, 4494-4496. [CrossRef]

28. Paul, K.; Guchhait, N. A quantum chemical computational insight into theintramolecular hydrogen bond interaction in an antibacterial drugmolecule-2-acetylindan-1,3-dione. Comput. Theor. Chem. 2013, 1012, $20-26$. [CrossRef]

29. Li, F.; Zhong, H.; Zhao, G.; Wang, S.; Liu, G. Adsorption of $\alpha$-hydroxyoctyl phosphonic acid to ilmenite/ waterinterface and its application in flotation. Colloids Surf. A Physicochem. Eng. Asp. 2016, 490, 67-73. [CrossRef]

30. Chai, J.; Head-Gordon, M. Long-range corrected hybrid density functionals with damped atom-atom dispersion corrections. Phys. Chem. Chem. Phys. 2008, 10, 6615-6620. [CrossRef] [PubMed]

31. Weigend, F.; Ahlrichs, R. Balanced basis sets of split valence, triple zeta valence and quadruple zeta valence quality for $\mathrm{H}$ to Rn: Design and assessment of accuracy. Phys. Chem. Chem. Phys. 2005, 7, 3297-3305. [CrossRef] [PubMed]

32. Somasundaran, P.; Fuerstenau, D.W. Mechanisms of Alkyl Sulfonate Adsorption at the Alumina-Water Interface. J. Phys. Chem. 1966, 70, 90-96. [CrossRef]

33. Fan, A.; Somasundaran, A.P.; Turro, N.J. Adsorption of Alkyltrimethylammonium Bromides on Negatively Charged Alumina. Langmuir 1997, 13, 506-510. [CrossRef] 
34. Frisch, M.; Trucks, G.W.; Schlegel, H.B.; Scuseria, G.E.; Robb, M.A.; Cheeseman, J.R.; Scalmani, G.; Barone, V.; Mennucci, B.; Petersson, G.A.; et al. Gaussian 09, Revision D.01; Gaussian, Inc.: Wallingford, CT, USA, 2013.

35. Lee, C.; Yang, W.; Parr, R.G. Development of the Colle-Salvetti correlation-energy formula into a functional of the electron density. Phys. Rev. B Condens. Matter 1988, 37, 785. [CrossRef] [PubMed]

36. Francl, M.M.; Pietro, W.J.; Hehre, W.J.; Binkley, J.S.; Gordon, M.S.; DeFrees, D.J.; Pople, J.A. Self-consistent molecular orbital methods. XXIII. A polarization-type basis set for second-row elements. J. Chem. Phys. 1982, 77, 3654-3665. [CrossRef]

37. Mulliken, R.S. Electronic Population Analysis on LCAO-MO Molecular Wave Functions. II. Overlap Populations, Bond Orders, and Covalent Bond Energies. J. Chem. Phys. 1955, 23, 1841-1846. [CrossRef]

38. Reed, A.E.; Weinstock, R.B.; Weinhold, F. Natural population analysis. Chem. Phys. 1985, 83, 735-746. [CrossRef]

39. Fukui, K.; Yonezawa, T.; Shingu, H. A Molecular Orbital Theory of Reactivity in Aromatic Hydrocarbons. J. Chem. Phys. 1952, 20, 1653. [CrossRef]

40. Chen, P.; Zhai, J.; Sun, W.; Hu, Y.; Yin, Z.; Lai, X. Adsorption mechanism of lead ions at ilmenite/water interface and its influence on ilmenite flotability. J. Ind. Eng. Chem. 2017, 53, 285-293. [CrossRef]

41. Zhai, J.; Chen, P.; Wang, H.; Hu, Y.; Sun, W. Flotability improvement of ilmenite using attrition-scrubbing as a pretreatment method. Minerals 2017, 7, 13. [CrossRef]

42. Zhong, H.; Liu, G.; Xia, L.; Lu, Y.; Hu, Y.; Zhao, S.; Yu, X. Flotation separation of diaspore from kaolinite, pyrophyllite and illite using three cationic collectors. Miner. Eng. 2008, 21, 1055-1061. [CrossRef]

43. Liu, C.; Hu, Y.; Cao, X. Substituent effects in kaolinite flotation using dodecyl tertiary amines. Miner. Eng. 2009, 22, 849-852. [CrossRef]

44. Jiang, H.; Sun, Z.; Xu, L.; Hu, Y.; Huang, K.; Zhu, S. A comparison study of the flotation and adsorption behaviors of diaspore and kaolinite with quaternary ammonium collectors. Miner. Eng. 2014, 65, 124-129. [CrossRef]

45. Jiang, H.; Xu, L.H.; Hu, Y.H.; Wang, D.Z.; Li, C.K.; Meng, W.; Wang, X.J. Flotation and adsorption of quaternary ammonium cationic collectors on diaspore and kaolinite. Trans. Nonferr. Met. Soc. China 2011, 21, 2528-2534. [CrossRef]

46. Dash, M.; Dwari, R.K.; Biswal, S.K.; Reddy, P.S.R.; Chattopadhyay, P.; Mishra, B.K. Studies on the effect of flocculant adsorption on the dewatering of iron ore tailings. Chem. Eng. J. 2011, 173, 318-325. [CrossRef]

47. Evenäs, L.; Furó, I.; Stilbs, A.P.; Valiullin, R. Adsorption isotherm and aggregate properties of fluorosurfactants on alumina measured by 19F NMR. Langmuir 2002, 18, 8096-8101. [CrossRef]

48. Kamyshny, A.; Lagerge, S.; Partyka, S.; Relkin, P.; Magdassi, S. Adsorption of native and hydrophobized human IgG onto silica: Isotherms, calorimetry, and biological activity. Langmuir 2001, 17, 8242-8248. [CrossRef]

49. Salako, O.; Lo, C.; Zhang, J.S.; Couzis, A.; Somasundaran, P.; Lee, J.W. Adsorption of sodium dodecyl sulfate onto clathrate hydrates in the presence of salt. J. Colloid Interface Sci. 2012, 386, 333-337. [CrossRef] [PubMed]

50. Zhou, Q.; Somasundaran, P. Synergistic adsorption of mixtures of cationic gemini and nonionic sugar-based surfactant on silica. J. Colloid Interface Sci. 2009, 331, 288. [CrossRef] [PubMed]

51. Li, M.; Wei, D.; Liu, Q.; Liu, W.; Zheng, J.; Sun, H. Flotation separation of copper-molybdenum sulfides using chitosan as a selective depressant. Miner. Eng. 2015, 83, 217-222. [CrossRef]

52. Fuerstenau, D.W.; Jia, R. The adsorption of alkylpyridinium chlorides and their effect on the interfacial behavior of quartz. Colloids Surf. A Physicochem. Eng. Asp. 2004, 250, 223-231. [CrossRef]

53. Somasundaran, P.; Krishnakumar, S. Adsorption of surfactants and polymers at the solid-liquid interface. Colloids Surf. A Physicochem. Eng. Asp. 1997, 123, 491-513. [CrossRef]

54. Koopal, L.K.; Lee, E.M.; Böhmer, M.R. Adsorption of cationic and anionic surfactants on charged metal oxide surfaces. J. Colloid Interface Sci. 1995, 170, 85-97. [CrossRef]

55. International Union of Pure and Applied Chemistry (IUPAC). Compendium of Chemical Terminology, 2nd ed.; Blackwell Scientific Publications: Oxford, UK, 1997; ISBN 0-9678550-9-8.

(C) 2017 by the authors. Licensee MDPI, Basel, Switzerland. This article is an open access article distributed under the terms and conditions of the Creative Commons Attribution (CC BY) license (http:/ / creativecommons.org/licenses/by/4.0/). 